\title{
Using Interactive Platform "Round" to Organize Online Leisure Activities for Children During the Pandemic
}

\author{
Leysan R. Kayumova ${ }^{1 *}$, Liliya N. Gainullina ${ }^{1}$, Roza Sh. Akhmadieva ${ }^{2}$, Valentin V. Matvienko ${ }^{3}$, \\ Ekaterina L. Kabakhidze ${ }^{4}$ \\ ${ }^{1}$ Kazan (Volga region) Federal University, Kazan, RUSSIA \\ ${ }^{2}$ Kazan State Institute of Culture, Kazan, RUSSIA \\ 3 Peoples' Friendship University of Russia (RUDN-University), Moscow, RUSSIA \\ ${ }^{4}$ Financial University under the Government of the Russian Federation, Moscow, RUSSIA
}

Received 2 March 2021 - Accepted 16 June 2021

\begin{abstract}
The speed with which interactive platforms are being modernized is increasing every year. The number of their users and consequently, the demand in such platforms are also rising. Quarantine restrictions and regulations related to COVID-19 revealed the problems of organizing both communication and leisure activities online. Since the advent of instant messengers in the 1990s, people have learned to communicate in a hybrid mode and to find friends over the Internet. Online communication, however, has always been occasional and could easily be switched to offline interaction. In view of the imposed restrictions during the pandemic, people were forced to stay isolated. The impact of the restrictions on organized leisure activities for children was also damaging. Online leisure activities were presented at best by online team games. Such online games, however, cannot replace the educational goals and learning outcomes of offline activities. From spring to summer 2020, all Russian schoolchildren and students studied online on various educational platforms. While several models of distance learning and teaching were implemented in the field of education (via Zoom, Microsoft Teams and other platforms), leisure activities were not adapted to an online format. At the same time, organized leisure activities are recognized as the main means for the socialization of children. It is noteworthy that the primary school age group became the most vulnerable. Our research aim was to analyze modern interactive platforms, identify their potential in organizing leisure activities, and determine the conditions for using the platform "Round" for leisure activities of primary school children. As a result of the study, the possibilities of introducing the platform "Round" for organizing leisure activities for children with different developmental levels and/or with difficult socio-economic conditions, who do not have the opportunity to receive additional education services, were identified.
\end{abstract}

Keywords: practice, digital resources, primary school children, teacher education

\section{INTRODUCTION}

The speed with which interactive platforms are being modernized is increasing every year. The number of their users and consequently, the demand in such platforms are also rising. The modern generation of children lives both in online and real worlds. Every day, many different means of communication such as mobile applications and messengers are used for different purposes. These are not only work- and educationrelated purposes, but also personal such as spending free time, escaping from real life, and relaxing. Thus, messengers and social networking sites (telegram, Instagram and others), initially intended for communication, have become a way of spending leisure time.

Quarantine restrictions and regulations related to COVID-19 forced people to stay isolated and move to an

(c) 2021 by the authors; licensee Modestum. This article is an open access article distributed under the terms and conditions of the Creative Commons Attribution License (http://creativecommons.org/licenses/by/4.0/). 


\section{Contribution to the literature}

- The research examined an interactive platform "Round" and the possibilities of its application in organizing online leisure for children during the lockdown.

- The authors developed video challenges about current professions that allow children to master a new profession in the format of a play. Children can understand the financial benefits of such professions as a home farmer, blogger, content manager.

- The research identified specifications of using the mobile application "Round" in Russian schools with children having different socioeconomic statuses.

- The results contribute to the organization of online leisure activities for children who do not have the opportunity to attend study clubs (sports schools, music schools and others) or who is homeschooled during the lockdown.

online world both to work and study. The Order of the Ministry of Science and Higher Education of the Russian Federation No. 397 as of March 14, 2020 identified the main modes of work for education establishments during the pandemic. According to this order, when implementing education programs, educational institutions had to organize interaction between students and university teachers exclusively in a digital educational environment (Ministry of Science and Higher Education of the Russian Federation, 2020). This way, educational activities at all levels of education were moved to online platforms such as Zoom and Microsoft Teams. These platforms helped to ensure a smooth transition from an offline to online format in a short time which did not interrupt the educational process. Organized leisure activities, however, experienced some difficulties.

The situation with restrictive measures introduced to prevent the spread of a new coronavirus infection affected students' leisure activities. Different study clubs had to either stop their activities or move online. The potential of interactive platforms, messengers, mobile applications and social networks is so high that children can master them skillfully and in no time following the step-by-step instructions from an early age (Begishev et al., 2021; Larionova et al., 2018; Nizamutdinova et al., 2019). Children get interested in digital devices and can spend all their free time using them. This way, the online format became the only solution for maintaining the education process during the lockdown. Overall, two groups of children, deprived of leisure activities during the pandemic, were formed. The first group of children attended study clubs regularly before self-isolation started. After that, their leisure time changed radically. The second group did not attend offline study clubs and spend their free time indoors and/or outdoors. They had no changes in organized leisure. Amidst the pandemic, however, both groups of children started to use gadgets more often which was often supported by their parents. This underlines the importance of having resources for leisure activities both offline and online. One of the answers to the above-described problem was the development of the interactive aggregator platform
"Round" (Round, n.d.) which made it possible to create an environment for online leisure activities. Importantly, the main distinguishing feature of the interactive platform "Round" is the security system which allows preventing negative aspects of social networking services such as bullying and others.

\section{Purpose and Objectives of the Study}

The research aimed to analyze modern messengers and mobile applications, identify their potential in organizing leisure activities, and determine the conditions for using the platform "Round" for leisure activities of primary school children.

The study was guided by the following research questions:

1. What are the most popular messengers and mobile applications used for games and communication among younger students?

2. Are there any specialized messengers and mobile applications for online leisure activities of children?

3. What are the conditions for the effective use of the platform "Round" for the purposes of online leisure activities of primary school children?

This study was carried out as a part of the pedagogical expert evaluation of the interactive aggregator platform "Round" in the Russian system of organized leisure activities for children and their early career guidance.

\section{Literature Review}

The concept of "leisure activities" is interpreted in different ways. In general, cultural and leisure activities are recognized as a complex system of spending free time by a person. According to Volovik and Volovik (1998), leisure activities represent a period of time freed from obligatory work and other non-negotiable responsibilities.

In Russian pedagogy, a widespread definition of a leisure activity was coined by Tregubov (1991). According to the scholar, it is a conscious and purposeful 
activity that allows a person to meet their own needs, choose personal interests and activities that help to bolster self-esteem and become self-fulfilled (Tregubov, 1991). Based on Tregubov's (1991) research, the specifics of the leisure of primary school children can be determined.

Leisure should be organized in such a way that 1) communication needs are met; 2) new knowledge is obtained, processed and assimilated; 3) skills and competencies are formed; 4) social status is raised; 4) socially useful work is performed; 5) early career guidance of the child is carried out (Zolotareva \& Sukhanova, 2013). The child's leisure is also defined as an instrument for implementing the State's social procurement. According to it, leisure should contribute to psychological and socio-economic stability, security of the society and the State; reduce social tension; create conditions for the prevention of disruptive behavior (Galchenko et al., 2020; Kopytin, 2003; Levina et al., 2019; Razumovskaya et al., 2018; Zolotareva \& Sukhanova, 2013).

Particular emphasis is paid upon the organization of children's leisure time online. With regard to the quarantine restrictions in today's world, one can say that everyday life has changed, and all human activities now take place either offline or online. In fact, "today's hobby crafts are frequently concerned with material mediated via the internet and accomplished with the aid of software, which also affects our understanding of maker identities in online communities" (Kouhia, 2020). This confirms that the demand for using online resources is also growing in leisure activities. One of the tasks in providing primary school children with high-quality leisure activities online is ensuring safety and accessibility. This way, McCrickard and Hobby (2006) suggest supporting online case studies that are aimed at assisting classroom learning and self-paced education. Activities at study clubs enable children to unleash their potential, develop and use creativity (Kudinov \& Karunas, 2018).

Chawla et al. (2021) highlighted the advantages of using mobile applications for the organized leisure activities of children. According to the scholars, "lockdown has revived the concept of "free time" that is important for introspection and creativity for children" (Chawla et al., 2021, p. 91). Hardly any child "would have learned 'new' skills, hobbies, music, leisure reading, playing indoor games, physical activity or spending quality time with elders" (Chawla et al., 2021). At the same time, Stoecklin et al. (2021) talk about the detrimental effect of extensive use of online forms of leisure. This group of researchers found that after a long uncontrolled time spent online during the lockdown, respondents experienced difficulties in socialization, resuming their usual leisure and hobbies, communicating with friends and engaging in real school life (Stoecklin et al., 2021).
Play is the leading activity, and it is important that the child adopts positive moral norms. There are various methods and kinds of online leisure activities via different applications that contain both entertaining and informative content. There arises, however, the problem of motivation. Online games are exciting for the child, while mobile applications with educational content are used only during classes. Hodges and Buckley (2018) together with many other researchers of play and game technologies recommend using the concepts of the taxonomy of player types developed by Bartle to increase motivation. Brain functions can change with the frequency of the child's play. While some games can increase the brain's efficiency, others can lead to gambling addiction, and the child can refuse other important things (friendship, school, family). There are several parts or types of games that produce corresponding effects. Some of these games can improve brain functions for the better, whereas other games can weaken children's brain functions and can be addictive (Rosyati et al., 2020). This is important as children's digital engagement is growing around the world, as well as concerns about whether it is healthy or harmful (Kardefelt-Winther, 2017).

Therefore, it is simply vital for society to develop preventive measures to deal with the consequences of restrictions similar to the current lockdown. It is also important to have tools for ensuring continuous education and leisure in an online format. In our study, we suggest using the platform "Round" for primary school students. The platform allows children to engage in leisure activities online without violating quarantine restrictions and regulations.

\section{METHODOLOGY}

\section{Research Methods}

1) semi-structured interviews to identify messengers and applications used for organized leisure activities that are most often used by children;

Semi-structured interviews consisted of two parts. The first part asked about individual characteristics and family life. The second part asked about attitudes toward leisure activities.

The guidelines for children include five questions. All questions can be grouped into two categories. The first category includes questions as to how long children use gadgets and whether this time is sufficient. The second category contains questions about offline study clubs, whether children attend such clubs and about the reasons for attending or not attending.

Interviews with parents were guided by eight questions divided into three groups. The first group of questions asked about the socioeconomic status of families and time spent together as a family. The second group contained questions about leisure activities of 
children. The third group of questions asked about reasons for not attending study clubs by primary school children.

2) interactive aggregator platform "Round" (Round, n.d.) used as the tool to organize children's online leisure.

The aggregator platform for children's career guidance with case studies and process orders from partner companies has a client-server architecture and consists of an Android app, Web client, server REST API, and administration subsystem. Web client is based on React.js. The platform uses the following components: Redux, ReduxToolkit, Axios, SCSS, Swipper. The server REST API is based on ASP NET 5. PostgreSQL 13 is used as a data storage system. The administration subsystem is implemented as a Web client based on Angular.js that uses the server REST API. The back-end REST API is accessed over a secure TLS 1.2 connection.

\section{Sample}

The research was conducted in school No. 81 in Kazan, multidisciplinary polylingual grammar school No. 180 in Kazan, and University grammar school in Elabuga. The study was carried out from September 2020 till April 2021.

The experimental group consisted of 16 first-grade students from school No. 81 in Kazan. This was an inclusive class group. Most of the students in this class group are from large, disadvantaged families and do not have an opportunity to attend extracurricular activities. This class group was chosen as experimental since this category of children needs additional support in socializing. Parental consent was obtained to conduct interviews and allow children to use "Round".

The control group included first-grade students from school No. 181 in Kazan and University grammar school in Elabuga. These children are from functional families and have access to various leisure activities. Schools have high student success rates. These schools organize children's leisure in traditional areas (music, football and others) and modern areas (robotics and others).

\section{RESULTS}

\section{Results of Semi-Structured Interviews}

\section{Interviews with children}

At the first stage of the research, we set to find out what messengers and mobile applications are used by modern primary school children. Then, it was necessary to determine the potential of messengers and mobile applications for organizing children's leisure activities. To achieve this goal, interviews had two main lines of questioning. The first focused on the gadgets and mobile applications that children most often used; the second on the reasons why children preferred particular applications and what advantages those applications had. As was mentioned above, there were groups of children from disadvantaged families who did not have their own gadgets; and groups of children from functional families who had their own gadgets but whose parents were against using them. The latter groups of children had only mobile phones without Internet access or smartwatches.

After interviewing primary school children about which messengers, mobile applications, social networking services, games, and interactive platforms they use more often, we obtained the following results (Figure 1).

According to the interview results, the majority of children use WhatsApp and play Minecraft, and fewer children use Viber. An equal number of respondents use TikTok and Instagram, but only $17.5 \%$ of respondents use YouTube.

A thematic analysis of the responses revealed the reasons for the frequent use of mobile applications.

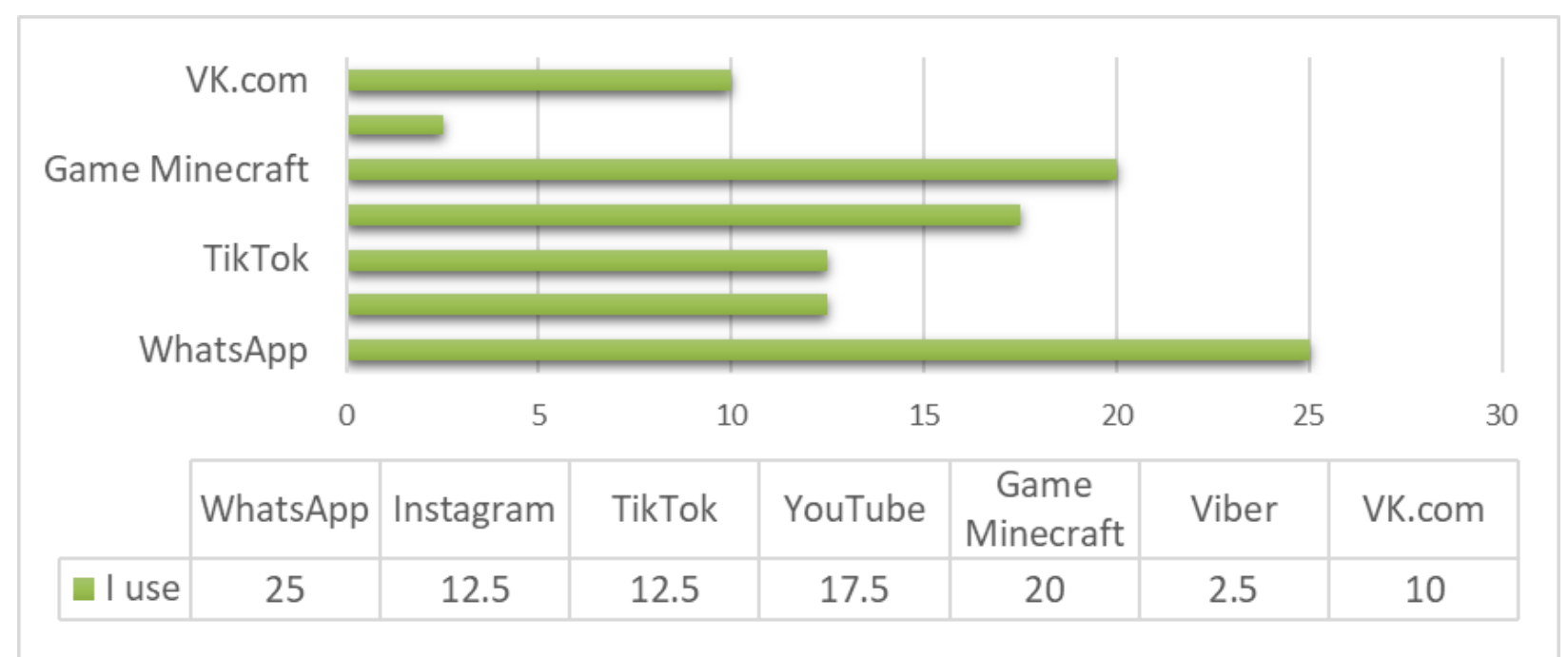

Figure 1. Interview results about messengers (children aged 7-8 years) (\%) 


\begin{tabular}{|l|l|l|}
\hline & & \\
\hline
\end{tabular}

Figure 2. Interview results about children's leisure (children aged 7-8 years) (\%)

According to the children's responses, they primarily use WhatsApp to communicate with their parents: "I have WhatsApp but I only use it to be in touch with my parents". Some children justified the use of WhatsApp by the teacher's request: "They post homework there"; "You can send a video and make a video call". There is no entertainment content on WhatsApp.

The next most used application was Minecraft. When talking about Minecraft, children often mentioned school and assignments. In Russian schools, Minecraft is used as an interactive digital playground for learning. The experimental group was introduced to Minecraft in September 2020. Since then, the students have had positive reviews. The respondents mentioned that "it is interesting to do homework", and "cool when the teacher asks to play the game in the classroom". However, children did not comment on using the game for extracurricular purposes.

The next popular mobile application was TikTok: “Well, I like making Tiktok videos, it's fun. But I do not know the purpose of that. You can get likes and watch other people's videos there." Another comment: "I have TikTok and I also want Instagram, but my mum does not allow that yet." These typical responses about TikTok show its popularity among children. A typical model for the desire to create an information feed has also been identified: children shoot videos, perform challenges and other tasks. Tiktok makes children interested in YouTube: "You can find the rest of the video on YouTube"; "You upload the video on YouTube and then, on Tiktok and Instagram". At the same time, children use YouTube to study game reviews: "I like YouTube. There are different videos and unboxing about games. I once watched an unboxing video and realized that a new game console is fun."
Many respondents mentioned that they like online and network games: "I like playing games; the levels of the game change interestingly, and new characters appear"; "I always want to play more"; "I always play my favorite game in the morning before school." However, many children did not mention the names of the games. During the interviews, it was revealed that parents scold children for playing but at the same time, they give their tacit consent: "My mum downloaded"; "They bought me a smartphone because I couldn't play on my old phone."

The interviews also showed that only $37.5 \%$ of all the respondents attended sports clubs, art schools and had organized leisure. During the lockdown, all children stayed at home: "I don't attend study clubs, my mum does not take me there. I stay at home and play on my phone or sometimes on my tablet. I rarely go outdoors as I do not have friends in our neighborhood".

\section{Interviews with parents}

After interviewing primary school children's parents, we obtained the results in Figure 2.

One of the tasks was to find out since what age the child uses gadgets, and how much time during a day the child spends using gadgets. The results show that on average, primary school children start using gadgets at the age of 7 and use them on average for less than 2 hours a day.

The following questions were aimed at identifying the reasons why children did not attend extracurricular activities (Figure 3).

The main reason for not attending study clubs was that no clubs matched the child's interests. Children 


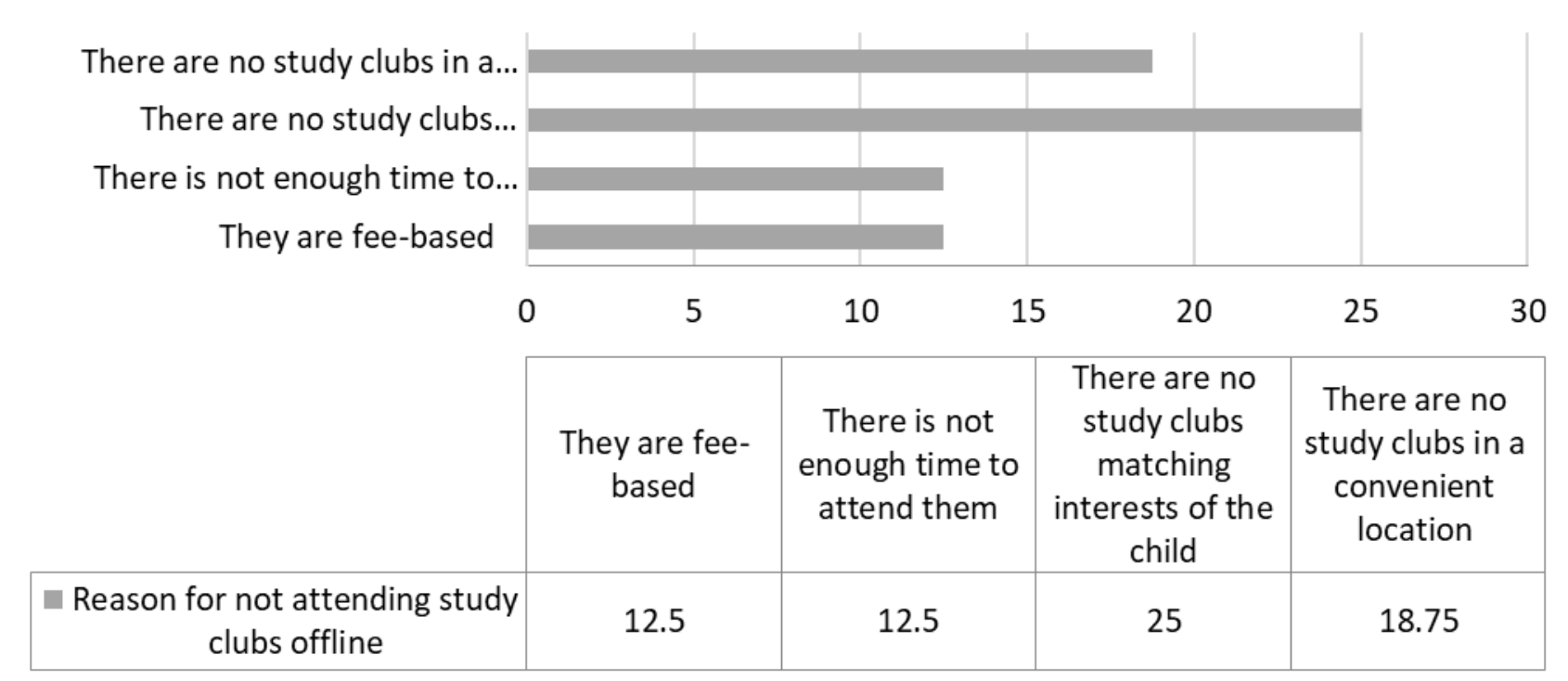

Figure 3. Interview results about children's leisure (children aged 7-8 years) (\%)

could not harness their talents and unlock their potential in existing clubs.

Parents were also interviewed about the child's leisure activities. In present-day conditions, parents view leisure as the time after school when children are engaged in the activities that they are interested in. During the interviews, parents talked mainly about offline leisure activities. They viewed online leisure as something unserious and harmful for children. Moreover, parents did not mention any designated platforms for online leisure. They justified their stance by claiming that children spend too much time with their gadgets.

Based on the results of interviews with primary school children and their parents, the following conclusions can be drawn:

1. WhatsApp users amount to $25 \%$ of all the respondents;

2. $12.5 \%$ of primary school children do not use gadgets;

3. $37.5 \%$ of primary school children attend offline study clubs;

4. $62.5 \%$ of primary school children are less active in their leisure time; they use gadgets (computers, tablets, mobile phones);

5. $50 \%$ of children use their gadgets for less than two hours of their leisure time per day;

The main reasons for not attending study clubs are a) no study clubs matching the child's interests; b) feebased study clubs; c) no study clubs in a convenient location; d) not enough time to attend study clubs.

\section{Results of the Analysis of the Aggregator Platform "Round"}

Interactive platforms, messengers and mobile applications are developed for users of all ages. These are often one-size-fits-all mobile applications. They interest and hold the attention of both a preschool child and a child of primary school age. Children get attracted by colorful design, background sounds, and the average rate of the conveyed information. The child wants applications to be interesting, fun, and fast-working.

Aggregator platform "Round" is designed as a gaming platform for organizing online leisure of children. It also has the function of early career guidance. To analyze the platform, we identified the following aspects: 1) self-motivation to use the platform; 2) platform's development potential and content.

Issues that "Round" is designed to tackle:

- Children residing in villages or small settlements know little about the most sought-after professions of the future;

- Children do not have sufficient opportunities to learn about new professions;

- Study clubs are often limited to fine arts, music, sports, which is not enough to reveal the child's creativity and talents.

Non-formal educational projects help find tools for influencing young people. This way, there is the opportunity to "highlight" areas of science and industry that will need more personnel in the future. Children, in their turn, have a chance to be in demand on the market in the future. 
Table 1. Correlation of player types and types of differentiated tasks

\begin{tabular}{|c|c|c|}
\hline Player types & Mental model & Types of differentiated tasks \\
\hline Researcher & \multirow[t]{3}{*}{ Reproductive thinking } & Observe something \\
\hline Motivation: a large number of different & & Repeat according to instructions \\
\hline game mechanics, diverse content and & & Repeat something already existing \\
\hline the possibility to use logic in the game. & \multirow[t]{4}{*}{ Divergent thinking } & Take something down \\
\hline Behavior pattern: researchers value & & Improve something \\
\hline knowledge, skills, quality content; want & & Complicated tasks \\
\hline to reveal secrets, develop talents, and & & Go beyond the existing \\
\hline have the most information about the & \multirow[t]{2}{*}{ Productive (creative) thinking } & DIY tasks \\
\hline game. & & Put forward a scientific theory and prove it \\
\hline Achiever & \multirow{2}{*}{ Reproductive thinking } & Gaining badges \\
\hline Motivation: accumulation of power, & & Boast about inventory, tools \\
\hline funds, objects, artifacts and other & \multirow[t]{2}{*}{ Divergent thinking } & Complicated tasks \\
\hline resources provided by the game. & & Go beyond the existing \\
\hline Behavior pattern: moneymakers, they & \multirow[t]{2}{*}{ Productive (creative) thinking } & \multirow[t]{2}{*}{ Collection of achievements (portfolio) } \\
\hline $\begin{array}{l}\text { like to acquire various goods, tend to } \\
\text { extract resources and produce things. }\end{array}$ & & \\
\hline Killer & \multirow[t]{2}{*}{ Reproductive thinking } & Competition with other players (in standard \\
\hline Motivation: superiority over other & & situations) \\
\hline $\begin{array}{l}\text { participants, presence of power and } \\
\text { advantages. }\end{array}$ & \multirow[t]{3}{*}{ Divergent thinking } & $\begin{array}{l}\text { Competition with other players (in non-standard } \\
\text { situations) }\end{array}$ \\
\hline Behavior pattern: they do not like tedious & & Complicated tasks in teams \\
\hline work, value dominance, like to & & Go beyond the existing \\
\hline $\begin{array}{l}\text { influence, compete, participate in } \\
\text { tournaments. }\end{array}$ & Productive (creative) thinking & Competition with other players \\
\hline Socializer & \multirow[t]{4}{*}{ Reproductive thinking } & Competition with other players Interactive tasks \\
\hline Motivation: communication with other & & with other players \\
\hline participants, being popular. & & Tell about something on a given topic Inviting \\
\hline Behavior pattern: they are almost always & & players to the community (friends) \\
\hline $\begin{array}{l}\text { peaceful, but in some situations, they } \\
\text { can start trolling; they avoid making }\end{array}$ & \multirow[t]{2}{*}{ Divergent thinking } & $\begin{array}{l}\text { Competition with other players Interactive tasks } \\
\text { with other players (initiator) }\end{array}$ \\
\hline difficult choices but help keep other & & Go beyond the existing \\
\hline participants and attract new ones. & \multirow[t]{2}{*}{ Productive (creative) thinking } & $\begin{array}{l}\text { Competition with other players Interactive tasks } \\
\text { with other players (mediator) }\end{array}$ \\
\hline & & $\begin{array}{l}\text { Share something about their own research/project } \\
\text { Comment/review on other people's works }\end{array}$ \\
\hline
\end{tabular}

\section{Motivation through gamification}

Considering the main motivation-related problems of game-based learning platforms such as uchi.ru and Minecraft, we first focused on the game technology of the platform "Round". Children using platforms uchi.ru and Minecraft consider these games as "exciting home assignments". However, no stable motivation for using these platforms as a leisure activity has been identified.

Game technology of "Round" is based on the concept of gamification in education. The aggregator platform has a set of differentiated tasks that take into account behavior patterns in the game (Bartle taxonomy of player types). The aggregator platform has various tasks with a sequential complication for players with different player types (Researcher, Achiever, Killer, Socializer). Each player type is guided by different motives and shows different behavior patterns in game situations. Also, the aggregator platform implements a model of sequential development of mental models (from reproductive, divergent thinking to productive creative thinking). There is also differentiation according to the level of education (correlation with age and basic education) and digestion of the materials learnt on the aggregator platform (correlation with the progress). The correlation of player types and types of differentiated tasks are presented in Table 1.

\section{Analysis of the content and operating principle of "Round"}

"Round" is designed taking into account the player types and provides the player with a set of tasks that focus on typical "professions" thus, immersing the child in the world of the profession. The target group of "Round" is modern schoolchildren who are commonly called "Generation Z" or "homelanders" (people born between the late 1990s and the early 2010s). Generation $\mathrm{Z}$ children value personal freedom. They tend to be independent and think about work quite early in life as they look for ways to become financially independent. At the same time, people from generation $\mathrm{Z}$ avoid working in areas that are not intertwined with digital technologies. Such areas are considered unfamiliar and futureless. They also do not choose creative professions since they believe that such jobs will soon disappear 


\begin{tabular}{|c|c|c|c|c|c|}
\hline \multirow{3}{*}{$\frac{n}{\overline{\frac{n}{n}}}$} & Data-scientist & & Chain of links & 4 & Likes and comments \\
\hline & Journalist & $\underset{0}{\infty}$ & Mood detector & $. \frac{}{\pi} \div$ & Gaining \\
\hline & $\begin{array}{c}\text { Biohacker } \\
\ldots\end{array}$ & 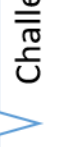 & $\begin{array}{c}\text { (profiling) } \\
\text { Weather forecast }\end{array}$ & $\frac{-\frac{0}{0}}{2} 3$ & $\begin{array}{l}\text { - signs, } \\
\text { - experience, } \\
\text { - game currency }\end{array}$ \\
\hline
\end{tabular}

Figure 4. Operating principle of the platform "Round"

because of universal automation. This generation values safety, family as the basis of everything, diversity in everything, entrepreneurship, science, investment in art, creativity, health care throughout life, food culture. Therefore, when organizing leisure time, it is necessary to take into account children's incentives and offer practice-oriented tasks that can meet their pragmatic goals.

There is specific rhetoric of the application (skill professional competence, challenge - video task, badge - a reward for completing a task). The platform's operating principle is presented in Figure 4.

As presented in Figure 4, first, the user chooses one or several "skills" - a profession or an area of professional activity. Then, the user's activity and progress are kept track of and stored in the Round database in the form of reports. Further, the child is given original tasks in a chosen area. In addition to specific professional skills, assignments allow children to acquire functional literacy. For example, the task "Mood detector" in the professional area "Journalist" aims at developing the skills of understanding interlocutors and predicting their behavior during the interaction. Each performed task is marked on the platform, and the user receives points, likes, and game currency for its completion.

Challenges (tasks) are grouped by skills (professions) and are presented in the form of short video challenges similar to TikTok videos. Completing tasks on a particular profession, the child can understand whether the profession is of interest if there are abilities and desire to perform it. After that, the results are analyzed, and data about each participant is accumulated. Each task has its own system of rewards. The child gains badges and can exchange them for real educational courses with official certificates (image-maker, photographer and other courses).

Communication on the platform is of particular importance. Children have the opportunity to evaluate each other's projects, comment and exchange ideas. At the same time, the interaction between children is mediated to prevent bullying. The platform creates a safe and favorable environment for users to communicate uniting them into interest groups.

The platform is based on the following main principles:
1. Expertise. All challenges (tasks) are developed by experts in psychology and education. The target group of users is represented by children, which means that proposed tasks must be appropriate as they give an impetus to develop in a specific professional area.

2. Children to children. Children themselves take an active part in creating content. They describe challenges in their "own" language, create examples of photo or video projects and design other tasks.

3. Volunteering. All experts work as volunteers understanding that they contribute to the education and nurturing of a new generation.

4. Compliance with the market needs. The skills are chosen after a thorough analysis of the market needs and competencies that will be in high demand in future, and at the same time, matching with the interests of the new generation. The target audience was studied based on the content of the Russian School of Generations Theory (2021).

Many different professions (skills) are accumulated on the platform "Round": mechanical engineer, blogger, journalist, photographer, beatmaker, good-doer, chef, illustrator, videographer, city farmer, zoologist, fashion designer, e-sportsman, biohacker, ecologist, animator, actor, entrepreneur, barista, beauty master, mobile app designer and others.

The main advantages of the platform "Round" are:

- Creative social environment;

- Assistance in discovering children's talents;

- Community of like-minded people keen on gamification;

- Space where children learn about modern professions and perform projects.

\section{DISCUSSION}

Mobile applications and messengers have undoubtedly become an important constituent of our life. Despite the age restrictions for registering on social networking sites, it is commonly known that the child first registers there at the age of 6 or 7 . This way, from a young age, the child undergoes two parallel processes of socialization: in real and virtual life. In our opinion, it 
would be wrong to consider only the negative aspects of online life. Binary socialization contributes to the development of a more mobile personality and expands communication circles. Moreover, if there existed no social networking sites, the circle of socialization agents would be characterized by a more homogeneous type of environment (similar values, communication styles). Thus, social networking sites can provide people with an opportunity to communicate with different people.

At the same time, one should be able to distinguish a wide range of risks that can be encountered on social networking sites including uncontrolled communication there. Anonymity, uncontrollability, emotional detachment creates the illusion of impunity and freedom from a code of ethics. That can ultimately lead to cruelty and criminalization of the individual.

Social media research should focus not only on identifying causal relationships of hazards, risks, and their impact. Rather, specific recommendations and practical projects regarding the safety issues of children and adolescents during online communication are of importance.

The benefit of using interactive platforms, messengers, social networking sites by primary school children can be achieved if:

1. There is a balance between entertainment and education. Every child's activity should ultimately be educational in nature. However, in order for it to be interesting, information needs to be presented in an entertaining way. This has a far-reaching effect on younger students;

2. The time and frequency of using gadgets is predetermined and fixed;

3. There is a practical orientation that is children receive information that will be useful to them in everyday life;

4. Children are motivated. To achieve that information should be presented in such a way that interests students. Being united in a study group should also motivate children.

\section{CONCLUSION}

Our research on the use of the interactive aggregator platform "Round" in organizing primary school children's leisure revealed the following: children enjoy online leisure activities on the platform; parents approve this kind of leisure activities; activities on the platform has both education and entertainment elements; primary school children begin to discover own talents and professional inclinations from an early age.

"Round" has an aim of early career guidance. It also guides children to choose professions that will be in demand in future. In addition, it contributes to the development of children's creativity, unlocking their potential and capabilities. By completing suggested tasks related to a particular professional area, children understand which profession interests them more. The platform also helps children to socialize and develop an integrated personality.

The platform users broaden not only their outlook but also their social circle and network of friends. Most importantly, the platform "Round" is safe, informative and interesting. Parents also view the platform as a good option for children to spend their leisure time under the conditions of today. The more structured children's leisure time is, the more children develop creativity, and the greater role is played by children's social activity as a system-forming quality of the personality (Turbina, 2007). Also, the more children act as doers during their leisure time, the more they develop their creativity (Sozinova, 2004).

However, there remains an issue with the effective implementation of the platform to the system of extracurricular activities in schools. It is necessary to provide free access to the platform both on Android and iOS devices. Then, the most critical problem is how to control time spent online and time using the platform. Provision for player types presents an opportunity for self-motivation to use "Round". At the same time, there exists the danger of becoming addicted and substituting a real world with a virtual world of the platform. Future research will focus on these limitations and the safe integration of the platform into the school's educational space.

Author contributions: All authors have sufficiently contributed to the study, and agreed with the results and conclusions.

Funding: This paper has been supported by Kazan Federal University and RUDN-University Strategic Academic Leadership Program.

Declaration of interest: No conflict of interest is declared by authors.

\section{REFERENCES}

Begishev, I., Khisamova, Z., \& Vasyukov, V. (2021). Technological, ethical, environmental and legal aspects of robotics. E3S Web of Conferences, 244, 12028.

https:/ / doi.org/10.1051/e3sconf/202124412028

Chawla, N., Sharma, P., \& Sagar, R. (2021). Psychological impact of COVID-19 on children and adolescents: is there a silver lining? The Indian Journal of Pediatrics, 88(1), 91-91. https://doi.org/10.1007/ s12098-020-03472-z

Galchenko, N. A., Shatskaya, I. I., Makarova, E. V., Kulesh, E. V., Nizamutdinova, S. M., Yudina, A. M., \& Skutelnik, O. A. (2020). Student hood spiritual needs in self-isolation period: Features and ways to meet them. EurAsian Journal of BioSciences, 14(1), 2229-2234.

Hodges, D., \& Buckley, O. (2018). Deconstructing who you play: Character choice in online gaming. 
Entertainment Computing, 27, 170-178. https:// doi.org/10.1016/j.entcom.2018.06.002

Kardefelt-Winther, D. (2017). How does the time children spend using digital technology impact their mental wellbeing, social relationships and physical activity?: an evidence-focused literature review. UNICEF Office of Research-Innocenti.

Kopytin, A. I. (2003). Delinquent behavior of minors. Gippokrat.

Kouhia, A. (2020). Online matters: Future visions of digital making and materiality in hobby crafting. Craft Research, 11(2), 261-273. https://doi.org/ 10.1386/crre_00028_1

Kudinov, I. V., \& Karunas, E. V. (2018). Model kruzhkovoy deyatelnosti $\mathrm{V}$ informatsionnoy obrazovatelnoy srede [The model of leisure activities in the educational information environment]. Bashkortostan Pedagogical Journal, 4(77), 135-142.

Larionova, A. A., Zaitseva, N. A., Anoshina, Y. F., Gaidarenko, L. V., \& Ostroukhov, V. M. (2018). The modern paradigm of transforming the vocational education system. Astra Salvensis, 6, 436-448.

Levina, I. D., Ukolova, L. I., Lavrentyeva, E. Y., Akhilgova, M. T., Zharikov, Y. S., Popova, O. V., Semyanov, E. V., Malanov, I. A., Muskhanova, I. V., Magomeddibirova, Z. A., Bazaeva, F. U., \& Isaeva M. A. (2019). Nursing home conditions for elderly people and its peculiarities of their adaptation. EurAsian Journal of BioSciences, 13(2), 1549-1555.

McCrickard, D. S., \& Hobby, L. (2006). A different case: An online multimedia system for teaching design and human-computer interaction. In EdMedia+ Innovate Learning (pp. 1064-1065). Association for the Advancement of Computing in Education (AACE).

Ministry of Science and Higher Education of the Russian Federation. (2020). Order of the Ministry of Science and Higher Education of the Russian Federation as of March 14, 2020 No. 397. https://minobrnauki. gov.ru/documents / ?ELEMENT_ID=18515

Nizamutdinova, S. M., Lisitzina, T. B., Vorobyev, V. K., Prokopyev, A. I., Tararina, L. I., \& Sayfutdinova, G.
B. (2019). Student views on downshifter lifestyle in urban environments. Humanities and Social Sciences Reviews, 7(4), 1196-1201. https:// doi.org/10.18510/ hssr.2019.74163

Razumovskaya, M., Zaitseva, N. A., Larionova, A. A., Chudnovskiy, A. D., \& Breusova, E. A. (2018). Prospects for applying various forms of organizational integration to improve the quality of education. Astra Salvensis, 6, 348-362.

Rosyati, T., Purwanto, M. R., Gumelar, G., Yulianti, R. T., \& Mukharrom, T. (2020). Effects of games and how parents overcome addiction to children. Journal of Critical Reviews, 7(1), 65-67. https://doi.org/ 10.22159/jcr.07.01.12

Round. (2020). Interactive aggregator platform. http:/ / newround.ru

Russian School of Generations Theory. (2021). https://rugenerations.su/

Sozinova, M. V. (2004). Dosugovaya deyatelnost kak sredstvo razvitiya tvorcheskogo potentsiala starshikh doshkolnikov (Doctoral dissertation). Herzen University, Saint-Petersburg. https://static.free referats.ru/_avtoreferats/01002624721.pdf

Stoecklin, D., Gervais, C., Kutsar, D., \& Heite, C. (2021). Lockdown and children's well-being: Experiences of children in Switzerland, Canada and Estonia. Childhood Vulnerability Journal, 1-19. https:/ / doi.org/10.1007/s41255-021-00015-2

Tregubov, B. A. (1991). Leisure time of youth: essence, typology, management. Publishing house of St. Petersburg University.

Turbina, T. A. (2007). Cultural and leisure activities as a means of developing social activity of modern adolescents (Doctoral dissertation). St. Petersburg State University of Culture and Arts, SaintPetersburg. https:/ / static.freereferats.ru/_avtorefe rats/01003331101.pdf

Volovik, A. F., \& Volovik, V. A. (1998). Pedagogy ofleisure. Flinta.

Zolotareva, A. V., \& Sukhanova, Yu. V. (2013). Results of the study of social procurement for additional education of children. Yaroslavl Pedagogical Bulletin, 2(2), 131-136.

\section{http://www.ejmste.com}

